\title{
CESPUC
}

\section{POESIA E MÚSICA EM PIER, DE SÉRGIO ALCIDES}

\author{
Juliana Cristina Carvalho*
}

\begin{abstract}
Resumo
O presente artigo apresenta considerações sobre a obra Píer, de Sérgio Alcides, com enfoque especial em seu diálogo com o universo da música. Para isso, nos dedicaremos a analisar o livro a partir da concepção de que toda arte aspira à condição de música e de que forma e substância não podem ser separadas uma da outra. Consideraremos, também, que a análise de um poema é a pesquisa das suas tensões, e é essa análise que pretendemos apresentar.

Palavras-chave: Literatura. Música. Poesia. Forma. Substância.
\end{abstract}

\section{POETRY AND MUSIC IN PÍER, BY SÉRGIO ALCIDES}

\section{Abstract}

This article shows considerations on Sérgio Alcide's book Píer with a special focus on its dialogue with the universe of music. To this end, we will analyze the book from the conception that all art aspires to the condition of music and that form and substance can not be separated from each other. We will also consider that the analysis of a poem is the research of its tensions and it is this analysis that we intend to present.

Keywords: Literature. Music. Poetry. Form. Substance.

* Pontifícia Universidade Católica de Minas Gerais. Doutoranda em Literaturas de Língua Portuguesa. Bolsista Capes. 


\section{Jutiana（bistina（abratho}

1 O SEMESTRE DE $2017-$ N. 30

\section{Introdução}

O presente artigo propõe reflexões acerca da obra Pier, de Sérgio Alcides, e de seu instigante diálogo com o universo da música, em especial com as suítes e os prelúdios. Antes de nos aventurarmos pela leitura dos elementos musicais do livro, apresentamos os pressupostos que orientam nossa leitura/análise.

No "Pensamento e poesia" da obra Esse ofício do verso, Borges (2000) retoma as concepções de Pater, Hanslick e Stevenson sobre as relações da poesia e da música. O crítico argentino sublinha que Walter Pater, ensaísta e crítico literário inglês, afirmou que toda arte aspira à condição da música. Isso porque, em música, forma e substância não podem ser separadas uma da outra. Ainda segundo Borges, o crítico austríaco Hanslick disse que a música é o idioma que nós podemos utilizar, entender, mas que não conseguimos traduzir; e Robert Louis Stevenson teria declarado que, num certo sentido, a poesia é mais próxima ao "homem comum, ao homem das ruas" (BORGES, 2000, p. 83), pois o material utilizado para a realização da poesia são as palavras e essas consistem no "próprio dialeto da vida". Na visão de Stevenson, como nos transmite Borges, as "palavras são usadas para os corriqueiros propósitos diários e são o material do poeta, tal como os sons são o material do músico". Prossegue colocando que, em tal afirmação, Stevenson fala das palavras como sendo "simples blocos, simples utensílios" transformadas pela literatura.

A respeito de tais concepções de Stevenson, Jorge Luiz Borges se posiciona:

Se aceitarmos o que diz Stevenson, temos uma teoria poética - uma teoria das palavras sendo feitas pela literatura para servir de algo além do seu uso intencional. As palavras, diz Stevenson, são destinadas ao comércio habitual do dia-a-dia, e o poeta de algum modo as converte em algo mágico. Suponho concordar com Stevenson, mas acho que ele talvez pudesse ser contestado. (BORGES, 2000, p. 84).

Borges contesta Stevenson ao discutir o caráter abstrato e concreto das palavras. O autor afirma que, por meio dele, descobrimos que as palavras não começaram abstratas, mas, sim, concretas - e acredita que, nesse caso, "concretas" apresente quase a mesma ideia que "poéticas". Para Borges "ao falarmos de poesia, podemos dizer que ela não faz o que Stevenson pensava - a poesia não tenta pegar um conjunto de moedas lógicas e transformá-las em mágica. Mas ela trata de levar a linguagem de volta às fontes”. (BORGES, 2000, p. 86). Borges considera que as palavras começam como mágica e são reconduzidas à mágica pela poesia (BORGES, 2000, p. 97).

Acerca das metáforas, Borges afirma que todas elas são produzidas pela ligação de duas coisas distintas, então, "[...] tivéssemos tempo suficiente, poderíamos formular uma soma quase inacreditável de possíveis metáforas" (BORGES, 2000, p 30). Referindo-se ao poeta argentino Lugones, especificamente ao prefácio de sua obra Lunario sentimental, Borges diz que, para o mencionado autor, cada palavra consiste em uma metáfora morta. Em seguida, declara: 


\section{CESPUC}

[...] Essa declaração, claro, é uma metáfora. Mas acho que todos sentimos a diferença entre metáforas mortas e vivas. Se pegarmos qualquer bom dicionário etimológico (estou pensando em meu velho amigo ignorado, dr. Skeat) e se procurarmos uma palavra qualquer, na certa encontraremos uma metáfora enfurnada em alguma parte. (BORGES, 2000, p. 31).

Refletindo ainda sobre a metáfora, sublinha que o relevante sobre ela é ser sentida pelo leitor ou pelo ouvinte "como" uma metáfora. Adiante, assegura que "toda literatura é feita de truques, e esses truques - a longo prazo - acabam sendo desvendados. E então os leitores se cansam deles" (BORGES, 2000, p. 39). Borges conclui o seu pensamento afirmando que cada metáfora é diferente. Segundo ele, toda vez que é usada, ela produz novas e distintas variações. Outra constatação é a de que existem metáforas que não podem ser reconduzidas a modelos já definidos. Ao serem empregadas, irão surpreender a imaginação dos leitores. Ao abordar a obra de Sérgio Alcides, partiremos dessas discussões trazidas por Borges a respeito da ideia de que "toda arte aspira à condição de música", da indistinção entre forma e substância própria da música. Teremos como base, também, a natureza metafórica de todas as palavras.

Do ponto de vista específico da análise dos poemas, acompanharemos os pressupostos trazidos por Candido em seu livro Na sala de aula. O crítico ao tratar da leitura analítica de um poema aponta duas leituras: a primeira, que se dedica aos "níveis da estrutura aparente", que visa constatar qual é a organização geral do poema, e a segunda, considerada um "nível profundo", que investiga as tensões que existem no interior do texto. Nas palavras do autor:

[...] a análise de um poema é frequentemente a pesquisa das suas tensões, isto é, dos elementos ou significados contraditórios que se opõem, e poderiam até desorganizar o discurso, mas na verdade criam as condições para organizá-lo, por meio de uma unificação dialética. (CANDIDO, 2000, p. 31).

Ainda refletindo sobre o poema, o crítico assegura que da mesma forma como as partes de um poema são elementos de um conjunto próprio, "[...] o poema por sua vez é um conjunto formado pelas circunstâncias da sua composição, o momento histórico, a vida do autor, o gênero literário, as tendências estéticas do seu tempo etc." (CANDIDO, 2000, p. 34). Apenas enxergando-o dessa maneira que estaremos habilitados e aptos a analisar o significado da forma mais abrangente e completa possível que, segundo ele, "[...] é sempre incompleta, apesar de tudo" (p. 34). Seguindo esses pressupostos, vamos ao livro de Sérgio Alcides.

\section{Contemplando o Píer}

Sérgio Alcides apresenta um projeto literário maduro, marcado por profundas e belas abstrações. Os poemas de Píer evidenciam uma liberdade formal, que faz parecer que o poeta menos procura uma forma precisa, e mais permite que as formas o encontrem, e, a sua poesia.

Píer parece trazer um estado de contemplação, de paixão, de paz, de calmaria, de silêncio, de concretude, de completude. Mas, toda essa impressão se desfaz ao se perceber, nos poemas, a locução lírica de um sujeito fragilizado, contraditório, angustiado, perturbado, inquieto, arranhado, líquido, fragmentado. 


\section{CESPUC \\ 1 O SEMESTRE DE 2017 - N. 30}

$\mathrm{O} \mathrm{BICHO}$

A mesa, a tela, o papel

é que estão iluminados, no pensamento é de noite.

(...)

Não sei o que está aqui, nem

Se isto sabe o que sou. Não

Sei se meus olhos enxergam

Por outro, num outro rosto

Onde a semelhança é breu.

(ALCIDES, 2012, P.17

Com um tom concreto, amargo, crítico e ao mesmo tempo, contemplativo, abstrato, onírico, fluido é que se sustentam as movimentações e contradições instaladas em Píer.

Desde a capa entramos em contato com a paisagem e seus elementos líquidos e sólidos, com as suas presenças e sombras - numa evidência do constante jogo entre sólidos e líquidos presentes nos poemas de Alcides.

Figura 1 Capa do livro Píer

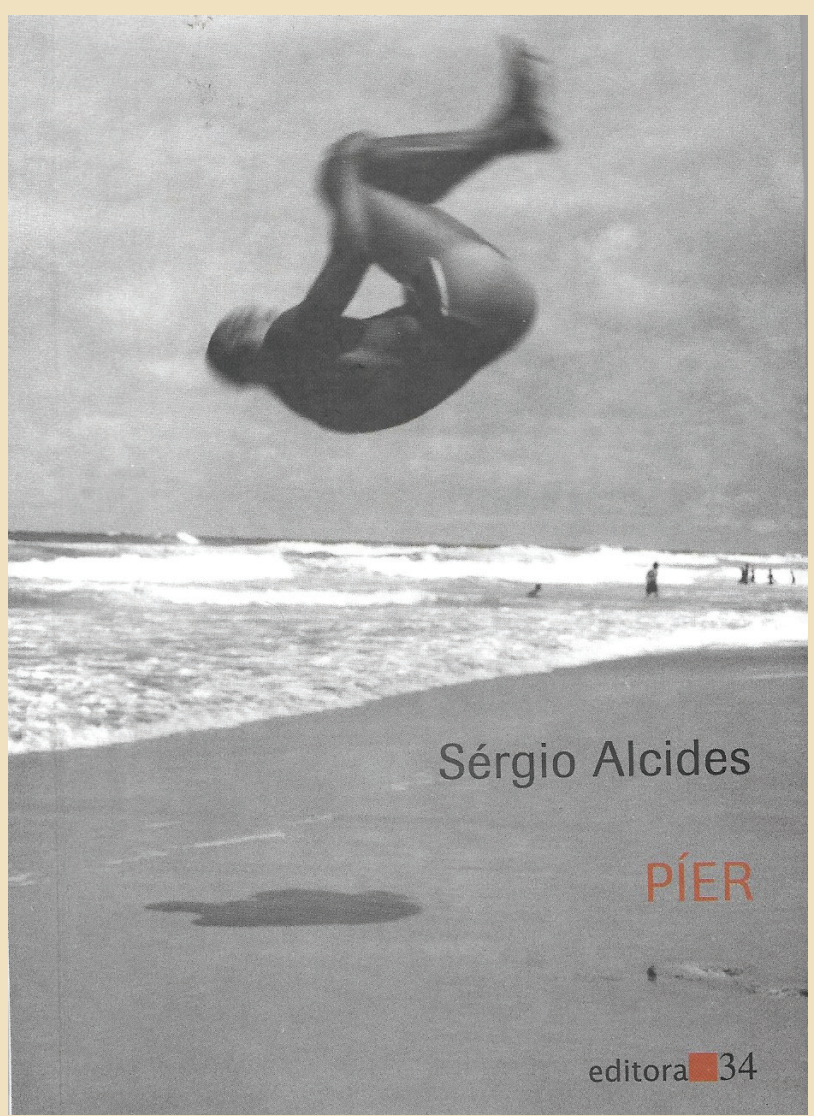

Fonte: Editora 34. Fotografia de Kristim Capp 


\section{CESPUC \\ 1 O SEMESTRE DE $2017-$ N. 30}

Para explicar a capa, o poeta afirma que a foto foi tirada por uma fotógrafa americana e que o flash conseguido por ela revela o que traz o livro: o "engajamento da poesia com ela mesma", com todas as possibilidades que a linguagem proporciona, com os limites da linguagem que se almeja combater, com os vícios da linguagem que se quer articular, ou sabotar. Esse, segundo ele, é o engajamento da poesia. ${ }^{1}$

Apresentando o píer como metáfora fundante e perfeita dos poemas do livro, Newton Bignotto diz:

[...] imagem de um lugar propício à meditação e/ou contemplação. Então, embora ofereça um estado de paz, a imagem que guarda em si, ao mesmo tempo, a contradição entre o peso das massas líquidas em constante mutação e a leveza de uma ponte sobre a qual se contempla a dissolução constante desse movimento. Metáfora perfeita para a poesia de Sérgio Alcides. (ALCIDES, 2012, orelha).

Bignoto, com essas palavras, oferece ao píer a condição de lugar-conceito da obra de Alcides. Bignotto afirma que se trata "[...] dos limites de um ser projetado como um embarcadouro em direção ao mar, objeto inextinguível de suas procuras e incertezas". Assegura também a presença de uma "consciência da fragilidade de nossa condição", e considera os versos:

[...] bem humorados e densos, recuperam a tópica clássica de meditação sobre a morte dialogando diretamente com os ossos e não com a sua simbologia; poemas auxiliam o poeta a testemunhar o fluxo ininterrupto do ser, de todos os seres. (ALCIDES, 2012, orelha).

O filósofo qualifica o universo da obra como sendo "poético sombrio e desafiador; ressoam nos versos indagações, que não podem ser feitas em nenhuma outra linguagem senão a da poesia" (idem). E afirma também que a obra:

[...] evoca a crueza mineral do solo, as praias, e a beleza do sertão; conduz também à violência das cidades brasileiras, que traga a vida de seus habitantes mais desprotegidos, como o mendigo Beleléu, personagem de um poema memorável. (ALCIDES, 2012, orelha).

Para consolidar o que diz Bignoto, transcreve-se o poema Beleléu:

\section{BELELÉU}

Beleléu não morava nos jardins.

Ele nunca foi flor que se cheirasse.

Ele era um cidadão, vivia em público.

Ele era um sujeito quase invisível.

(por causa do "quase", morreu de tiro).

Fervia o seu miojo numa lata

Que não foi ele quem esvaziou.

Fumava ponta, fazia discurso.

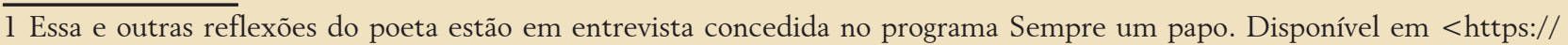
www.youtube.com/watch?v=pwyCOljbaCI> (acesso em julho/ agosto de 2016). 


\section{CESPUC \\ 1 O SEMESTRE DE 2017 - N. 30}

Bebia na calçada - com o santo.

Pendurava a roupa lavada no trópico.

Guardava no bueiro sua coleção

De ex-mercadorias, relíquia de ruínas

Em fragmentos de porquês arrebentados.

(ALCIDES, 2012, p. 69)

Com esses versos observamos como se constrói a principal metáfora da obra: a contemplação do homem sobre o homem, a tensão advinda da paisagem dramática, a exibição pública da miséria e a percepção da morte.

\section{Forma e substância: palavra e música}

Coloquemos a estrutura da obra em foco. Píer é composta em quatro partes, três delas organizadas como suíte: "Ossada"; "Píer"; "Margem do São Francisco". No campo da música, a suíte é uma peça musical de natureza instrumental. É uma sequência de movimentos de dança, todos na mesma tonalidade, mas com variação no andamento. Na obra de Alcides, as suítes se constituem como um conjunto de poemas curtos, que tratam de assuntos semelhantes, por exemplo, na primeira suíte "Ossada", verificam-se vários 'movimentos'/poemas tematizando o processo de decomposição do homem, como se evidenciasse um modo de ser em ruínas, são eles: "Ossada", "Jazem", "Pernas de verso", "Interpretação", "Drama". São cinco poemas curtos, o tema geral abordado é o processo de arruinamento/ morte do ser - é o tornar-se ossos/ ossada. A estrutura presente não é marcada por rigidez de métricas e rimas. Há espaçamentos, silêncios, e os versos são dispostos na página como fragmentos (ossos?).

Pensamos que a organização temática da suíte "Ossada", a natureza dos 5 poemas que a compõem retomam a definição de suíte musical, a nosso ver: são movimentos diferentes em uma mesma tonalidade, a degradação. Ossada, em seu sentido denotativo indica destroços, restos, ruínas, fragmentos, ossos. Remete, logo, à morte. Os primeiros versos do poema indicam:

Os ossos morrem primeiro, a carne é forte.

Pálida vocação para restos imóveis e gravíssimos!

(ALCIDES, 2012, p. 81)

Como podemos perceber, o poeta, por meio dessa abertura, já anuncia uma inversão de ideias, pois o ditado popular diz que é a carne que é fraca. Mais adiante, tal movimento se repete:

Os enterrados por dentro da vida, os tímidos,
os empurrados ossos da carne que quer amar.

(ALCIDES, 2012, p. 81)

Da maneira como são estruturados e dispostos, a impressão que temos é a de que cada verso consiste em uma parte da explicação acerca do que é ossada e de que ossada trata o poema: 


\section{CESPUC \\ 1 O SEMESTRE DE $2017-$ N. 30}

Mudos como um santo, brancos como a hóstia. Os hieráticos que dançam por obrigação, só os ossos - os hóspedes involuntários - perpetuam em suspenso os nossos mais prudentes pensamentos e ao ridículo gesso preferem logo uma pá de cal.

(ALCIDES, 2012, p. 81)

Há, também, um paradoxo importante no interior dos versos. A ideia de ossada apresentada encontra-se nos "tímidos", que são caracterizados como os "enterrados por dentro da vida", nos "hieráticos que dançam por obrigação", ou seja, corpos vivos, porém, simbolicamente, segundo o poeta, mortos. No poema encontramos um jogo entre o abstrato e o concreto. Trata-se do processo de degradação do homem em vida. Como um processo de exumação. $\mathrm{O}$ contato de vida e morte presente é muito estreito, é o ato de desenterrar o corpo para ver como ficou; entre o que morre e o que vive na matéria animada e inanimada com todas as suas implicações, desafios, beleza, leveza, dureza, ambiguidade.

Passemos à análise do poema "Prelúdio", outro poema que evidencia a aproximação da obra de Alcides com elementos das formas musicais. No universo musical, prelúdio é definido como:

Um gênero musical de obra introdutória de outras obras maiores, geralmente uma ópera ou balé. Difere-se da abertura por antecipar temas da obra que antecede; normalmente, nas aberturas, os temas não se repetem no decorrer da obra. $\mathrm{Na}$ época medieval, os alaudistas tocavam o prelúdio como forma de aquecer, e preparar a tonalidade. Na época de J. S. Bach, o nome "prelúdio" era usado também para a introdução de uma fuga ou tocata. Chopin também escreveu vários prelúdios, mas nesse caso os prelúdios são apenas peças para poupiano, de forma livre, sem introduzir outra obra maior. ${ }^{2}$

Essa escolha do autor por iniciar com o Prelúdio, e não com um prólogo, enfatiza a ideia de que a poesia é música. Em Píer, o poema de iniciação atua como um prelúdio na música, pois antecipa temas que irão aparecer nos poemas seguintes e, também, funciona como um aquecimento.

\section{PRELÚDIO}

Tudo quietude, tudo

flutua sem sombra, sem

nenhuma ponderação.

O sono dos animais

em seus corpos recolhidos

imita a respiração

macia das almofadas,

e os sofás já se esqueceram

de toda a conversação.

$O$ pêndulo apenas pensa

no pulso, dentro da caixa.

Salta da parede o branco

2 (https://pt.wikipedia.org/wiki/Prel\%C3\%BAdio acesso em julho/ agosto de 2016) 


\section{CESPUC \\ 1 O SEMESTRE DE 2017 - N. 30}

na frente das coloridas telas, que vão se despindo de seu alarde, de sua murmuração.

\section{E, em silêncio, detém-se o filho do jato, claro, tubular, isento, e, súbito, sem retorno, espeta a mão no minuto. \\ (ALCIDES, 2012, p. 9)}

O poema se detém na reflexão do homem no mundo, com os seus anseios, sentimentos de vazio, da morte/ do passar do tempo, a dureza da vida, do existir. No poema, alguns desses temas já são apresentados ao leitor, antecipando o que virá no livro.

No poema, a música perpassa todos os versos, tal como no livro todo. Nele notamos uma rigorosa escolha lexical, rimas e ritmos que conferem densidade ao trabalho sonoro da composição literária de Sérgio Alcides. Dentre essas escolhas temos a presença das rimas, como em "tudo"/ "tudo", "ponderação"/ "respiração"/ "conversação", as aliterações como em "tudo"/ "tudo"/ "pêndulo"; "apenas"/ "pensa", as assonâncias em "apenas"/ "pensa", por exemplo.

A imagem que o poema nos traz é semelhante a uma pintura abstrata. O clima apresentado é onírico, do campo da abstração. Há uma densidade semântica das palavras utilizadas; uma espécie de polissemia que flutua.

Os sons presentes, também se contrastam com os silêncios marcados por expressões como "Tudo quietude", "flutua", "sonos", "pêndulo apenas pensa/ no pulso/, dentro da caixa", "/em silêncio,/ detém-se o filho do jato". Com essas formações, o pêndulo, que poderia ser uma imagem concreta, clara, óbvia, da forma como aparece, torna-se abstrato.

O segundo texto, seguinte ao apresentado, é "Está caindo". Ele mantém um pouco o ambiente, o tom, o clima, do anterior.

Querer olhar para a lente, verificar a ranhura

da lente, não a que arranha

do outro lado da vista

o mundo menos real

- mas real- da circunstância.

Sem poder deixar de ver

- através- a poesia.

Poeira que está caindo, cobrindo as mercadorias.

(ALCIDES, 2012, p. 10). 
O poema, como o próprio título diz, retrata um processo, algo em andamento. O tema abordado, de maneira geral, é o da constatação da poesia. Assim como no primeiro, há o predomínio da abstração e de movimento: no primeiro, resgatando aspecto já apresentado, mesmo com as imagens que conferem uma ideia de falta de movimento, há também, pelo ritmo, pelo verso final, a presença de movimento. Nada é muito claro, evidente, único há um duplo de concepções, digamos assim: cor $\mathrm{x}$ ausência de cor; falta de movimento $\mathrm{x}$ movimento; concreto x abstrato. Em "Está caindo", notamos a presença de sons mais rígidos, duros, "ranhura", "arranha"- algo que incomoda, que se encontra na "lente", é um traço, uma veia que norteia, uma marca, um corte. Esse "algo que incomoda" se encontra na lente que "arranha" o "mundo real". É "através" de tal mundo que vemos a poesia. O poema parece dizer que a linguagem não dá conta do mundo. Logo, há um conflito sugerido e, por conseguinte, um sujeito em conflito, tenso e denso, também, com questões profundas, complexas, existenciais.

Podemos ler o poema, também, como sendo uma fotografia - a presença do termo "lente" permite tal leitura-. O episódio retratado pode ser tido como um flagrante do momento no qual o poeta descreve o próprio ato de fotografar, captar, mostrar, refletir sobre aquilo que a lente capta/ alcança. A "poeira que está caindo" pode representar a desmaterialização "ganhando corpo", "cobrindo a mercadoria"- materializando-se, digamos assim. E essa imagem, no poema, representa, assim acreditamos, a própria poesia, a sua concepção. Assim, a poesia é simbolizada/ retratada como o ato direto de ver. Procurando novas leituras para a imagem "querer olhar para a lente, / verificar a ranhura", elaboramos que essa pode ser apreendida como o gesto de um olhar invertido da realidade, uma outra forma de leitura.

A nosso ver, o poema pode representar uma espécie de confissão metalinguística- é uma reflexão sobre o próprio processo de escrita/ produção-, simbolizado pelo ato da visão, de verfalar sobre o ato de ver, por meio da visão-.

Em resumo, o que o poema em análise propõe é um jogo entre a concepção de conceito e coisa. E o que conclui, mostra, é que não se trata de um jogo simples, harmônico, pois, nem sempre, as coisas do "real" são apreensíveis por meio da linguagem, da palavra. É a tensão do "real" como mercadoria, coisa, e como conceito, abstrato.

\section{Considerações finais}

Após todas as reflexões apresentadas e as leituras e interpretações dos poemas, percebemos como as metáforas; mesmo aquelas constantemente e exaustivamente repetidas, as "mortas", retomando ideia de Borges - podem auxiliar no processo de criação de novas, inúmeras, imagens literárias/ poéticas.

Sérgio Alcides utiliza a linguagem, as metáforas, de uma maneira diversa do senso comum, e, assim, além de conferir vida e mágica ao seu universo literário, realiza reflexões importantíssimas acerca da própria poesia e do processo de escrita. Porém, importante retomar e frisar, não se apresenta como um comandante seguro, firme, sob controle de sua embarcação, mas, sim, como alguém que é fortemente influenciado, inebriado, seduzido, domado, e tomado 


\section{CESPUC \\ 10 SEMESTRE DE 2017 - N. 30}

pelas fortes correntezas marítimas literárias. E tudo isso é feito mantendo uma espécie de natureza musical em sua poesia, por ela trazer a indissociabilidade entre forma e substância, entre palavra e música.

\section{Referências}

ALCIDES, Sérgio. Píer. São Paulo: Editora 34, 2012.

ALCIDES, Sérgio. Píer. In: Nova Literatura- Sempre um papo. Disponível em $<$ https://www. youtube.com/watch?v=pwyCOljbaCI > (acesso em julho/ agosto de 2016).

BORGES, Jorge Luís. Pensamento e poesia. In: BORGES, Jorge Luís. Esse ofício do verso. Organização Calin Andrei Mihailescu. Tradução de José Marcus Macedo. São Paulo: Companhia das Letras, 2000. P. 82-101.

BORGES, Jorge Luís. A metáfora. In: BORGES, Jorge Luís. Esse ofício do verso. Organização Calin Andrei Mihailescu. Tradução de José Marcus Macedo. São Paulo: Companhia das Letras, 2000. P. 29-50.

CANDIDO, Antonio. O estudo analítico do poema. 6.ed. São Paulo: Editorial Humanitas, 2006. 161p.

CANDIDO, Antonio. Uma aldeia falsa. Na sala de aula: caderno de análise literária. São Paulo: Ática, 8.ed,1989, p. 21-28. 